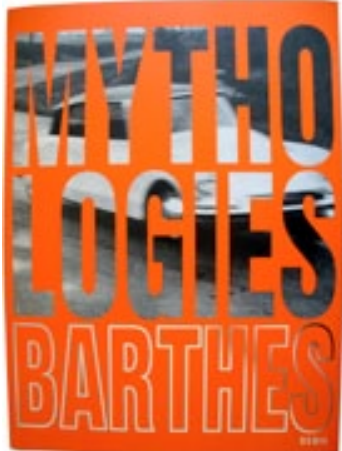

\title{
Mythologies, edição ilustradíssima
}

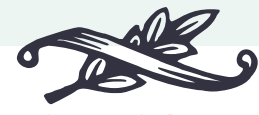

BARTHES, Roland. Mythologies. Edição ilustrada por Jacqueline Guittard. Paris: Seuil, 2010. (1957)

Cinquenta e quatro anos após sua publicação, Mythologies, de Roland Barthes, ganha uma retumbante edição ilustrada. O volume original compunha-se de uma coleção de textos publicados em diversos periódicos entre 1953 e 1956, nos quais Barthes propunha-se a analisar o funcionamento mitológico de temas contemporâneos da sociedade francesa - da tipificação do crime de um homem que assassinara os pais à publicidade de sabão para lavar roupas.

Omo en utilise deux [états-valeurs], assez nouveaux dans l'ordre des détergents: le profond et le mousseux. Dire qu'Omo nettoie en profondeur (voir la saynète du Cinéma-Publicité), c'est supposer que le linge est profond, ce qu'on n’avait jamais pensé, et ce qui est incontestalement le magnifier, l'établir comme un objet flatteur à ces obscures poussées d'enveloppement et de caresse qui sont dans tout corps humain. (p. 36)

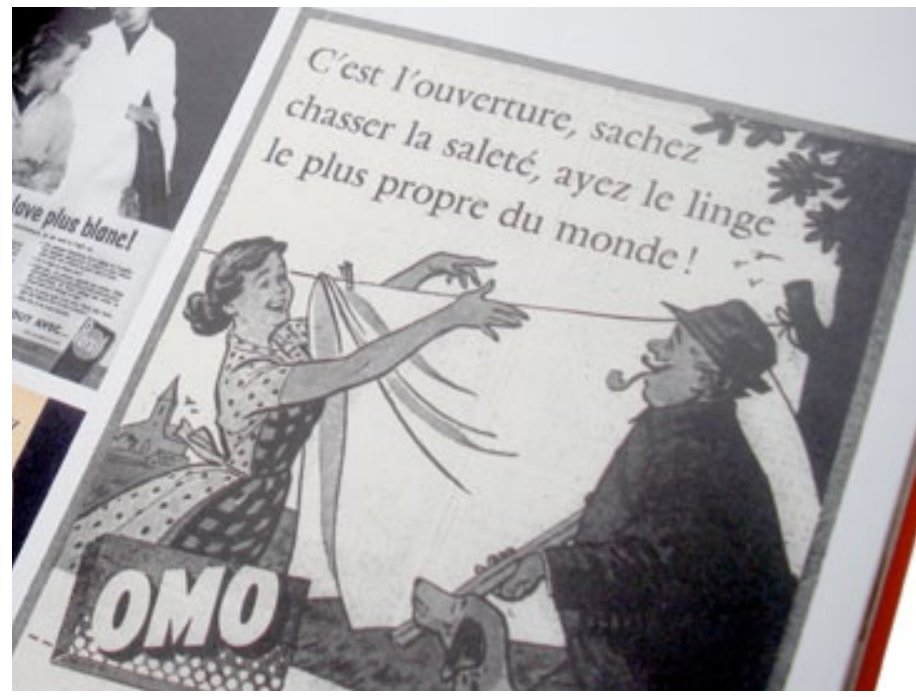

Podemos compreender "funcionamento mitológico" como naturalização: cristalização de certos critérios de valor que investem objetos, situações etc. de noções abstratas como Bondade e Justiça. Por este processo, certos objetos são deslocados para fora da história (interação social e relações de poder) e seu valor é tido como evidente (imutável e inquestionável). Mythologies foi redigido e publicado durante o período ${ }^{2}$ em que Barthes dedicou-se explicitamente ao combate da Doxa, o senso comum e/ou ideias vigentes. Com meios e fins didáticos e conscientizadores, Barthes mitólogo esmiúça, não sem humor, potencialidades do funcionamento ideológico daquilo cuja interpretação social era tida como dada, além ou aquém de questionamento para o público francês leitor do hebdomadário ParisMatch $^{3}$ na década de 1950. Em cada ensaio, ele redescobre a moral pequeno-burguesa entranhada nas insignificâncias contemporâneas e nos grandes acontecimentos.

$\alpha<\alpha<<<<<<<<<<<<<<<<<<<<<<<<<<<<<<<<<<<<<<$

${ }^{1}$ Graduada em Letras-Francês pela USP (2011) e Comunicação Social com Habilitação em Multimeios pela PUC-SP (2007). Infectada durante Iniciação Científica, prepara projeto de mestrado envolvendo Roland Barthes. Membro do grupo Criaçãi \& Crítica E-mail: pris_plo@yahoo.com.br

${ }^{2}$ A periodização da obra de Barthes pode ser um tanto controversa (para discussão, veja ROGER, P., 1986, Cap. II "Roland Barthes ou l'involution créatice" - p. 47-157); seguindo o quadro definido pelo próprio autor em 1975 (1995, p. 129), Mythologies integra a fase que tem como tema a mitologia social e como interlocução (Gide), Sartre, Marx, Brecht e Saussure.

${ }^{3}$ Ao arriscar uma equivalência brasileira, penso em um misto de Veja e Caras, revistas de alta penetração, formadoras de opinião e objetos de interesse. De 1949 a 2008, o slogan de Paris-Match foi "Le poids des mots, le choc des photos" (O peso das palavras, o choque das fotos), substituído desde 2009 por "La vie est une histoire vraie" (A vida é uma história verídica). 
Ce mythe de la « condition humaine » repose sur une très vieille mystification, qui consiste toujours à placer la Nature au fond de l'Histoire. Tout humanisme classique postule qu'en grattant un peu l'histoire des hommes, la relativité de leurs institutions ou la diversité superficielle de leur peau (mais pourquoi ne pas demander aux parents d'Emmett Till, le jeune nègre assassiné par les Blancs, ce qu'ils pensent, eux, de la grande famille des hommes?), on arrive très vite au tuf profond d'une nature humaine universelle. L'humanisme progressiste, au contraire, doit toujours penser à inverser les termes de cette très vieille imposture, à décaper sans cesse la nature, ses « lois » et ses « limites » pour y découvrir l'Histoire et poser enfin la Nature comme elle-même historique. (p. 207)

A unidade do conjunto advém do método, que também resiste melhor à passagem do tempo. A empreitada do mitólogo consistiria em expor o significado segundo que faz com que o signo funcione como mito, bem como as estratégias retóricas desse parasitismo. Apesar de emprestar da línguística o jargão, o método semiológico proposto por Barthes possibilita a análise de uma grande variedade de objetos, em especial fotografias. Portanto, um dos principais pontos de interesse da iniciativa de ilustrar Mythologies é justamente uma recontextualização das análises barthesianas: disponibilizar ao leitor produtos midiáticos (fotografias, textos jornalísticos, mensagens publicitárias) com os quais
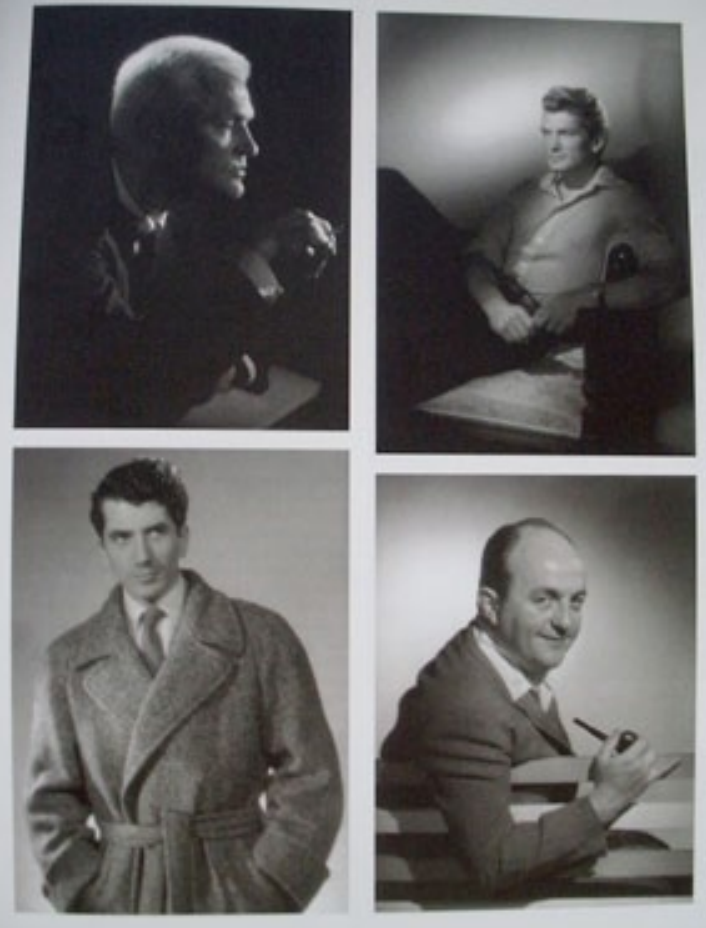
dialogava o mitólogo. Para tanto, Jacqueline Guittard, Maître de Conférences na Universidade de Picardie Jules Verne, reuniu ao longo de sua pesquisa de doutorado documentos que satisfizessem certas contraintes: obrigatoriamente contemporâneos dos textos barthesianos, preferencialmente com traços referidos por Barthes nas mitologias. Deles compõem-se as ilustrações da nova edição, de desconfortáveis dimensões $335 \times 246 \times 27 \mathrm{~mm}$ (altura x largura x profundidade).

As imagens ilustrativas beneficiam especialmente o leitor estrangeiro e/ou não contemporâneo das análises. Os atributos discutidos em L'acteur d'Harcourt, que analisa imagens de celebridades fotografadas por um determinado estúdio, saltam aos olhos nas ilustrações selecionadas por Guittard: são retratadas características, categorias, sob os nomes de indivíduos. Para ilustrar La grande famille des hommes (citada acima), em que Barthes discute uma exposição de fotografias do que haveria de comum entre as pessoas pertencentes às comunidades de diversas partes do planeta, há o pôster da exposição. $\mathrm{O}$ mesmo texto traz também um caso particular de ilustração: Barthes repudia a proposta da exposição, de que haveria uma natureza fundamental dos homens; Guittard privilegia o comentário sobre o tema e acrescenta ao repertório do leitor uma fotografia que contextualiza o argumento barthesiano - no caso, de uma vítima de racismo contemporânea.

Nos livros publicados por Barthes em vida, a associação entre texto e imagens foi tratada com grande cuidado: em L'empire des signes não há legendas (instruções de leitura imagética); em Roland Barthes par Roland Barthes, a legendagem é sobretudo irônica. Em La chambre claire, a fotografia mais comentada no livro nos é escondida; Barthes recusa-se a submeter seu olhar amoroso sobre a mãe à validação do leitor, se furta a pré-estabelecer nele uma relação com a verdade suprema do afeto-motor da escrita. A ilustração de Mythologies não se propõe a este tensionamento: é científica (feliz) na 
